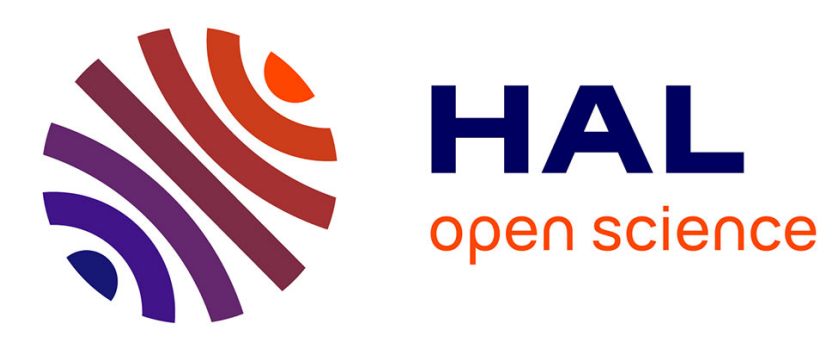

\title{
Molecular Selectivity of CO-N 2 Mixed Hydrates: Raman Spectroscopy and GCMC Studies
}

\author{
C. Petuya, A. Patt, J. M Simon, Sylvain Picaud, J. M Salazar, A. Desmedt
}

\section{To cite this version:}

C. Petuya, A. Patt, J. M Simon, Sylvain Picaud, J. M Salazar, et al.. Molecular Selectivity of CO-N 2 Mixed Hydrates: Raman Spectroscopy and GCMC Studies. Journal of Physical Chemistry C, 2020, 124 (22), pp.11886-11891. 10.1021/acs.jpcc.0c01315 . hal-02989303

\section{HAL Id: hal-02989303 https://hal.science/hal-02989303}

Submitted on 5 Nov 2020

HAL is a multi-disciplinary open access archive for the deposit and dissemination of scientific research documents, whether they are published or not. The documents may come from teaching and research institutions in France or abroad, or from public or private research centers.
L'archive ouverte pluridisciplinaire HAL, est destinée au dépôt et à la diffusion de documents scientifiques de niveau recherche, publiés ou non, émanant des établissements d'enseignement et de recherche français ou étrangers, des laboratoires publics ou privés. 


\section{Molecular Selectivity of CO-N $\mathrm{N}_{2}$ Mixed Hydrates:}

\section{Raman Spectroscopy and GCMC Studies}

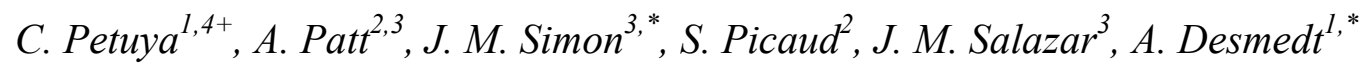

1) Groupe Spectroscopie Moléculaire, Institut des Sciences Moléculaires, UMR 5255,

CNRS, Université de Bordeaux, 351, cours de la Libération F-33404 TALENCE

Cedex, France.

2) Institut UTINAM, UMR 6213, CNRS, Université Bourgogne Franche-Comté, F25000 Besançon, France.

3) Laboratoire Interdisciplinaire Carnot de Bourgogne, UMR 6303, CNRS, Université de Bourgogne Franche-Comté, F-21078, Dijon Cedex, France.

4) NASA Jet Propulsion Laboratory, California Institute of Technology, 4800 Oak Grove Drive, Pasadena, California, 91109, United States.

\section{Corresponding Author}

*arnaud.desmedt@u-bordeaux.fr; jmsimon@u-bourgogne.fr

${ }^{+}$present address: NASA Jet Propulsion Lab. 
ABSTRACT. This paper reports a novel quantitative investigation concerning the COselectivity properties for mixed $\mathrm{CO}-\mathrm{N}_{2}$ hydrates. The study was developed by combining Raman Scattering experiments and Grand Canonical Monte Carlo simulations. Both approaches advocate in favor to say that mixed $\mathrm{CO}-\mathrm{N}_{2}$ hydrates are $\mathrm{CO}$-selective and quantitatively compare with regard to the measured and calculated molecular selectivities. Intriguingly, this preferential $\mathrm{CO}$ encapsulation is enhanced by decreasing the $\mathrm{CO}$ molar fraction of the gas mixture. Here, an original explanation to this peculiar behavior is provided in terms of a structural change of the clathrates from SI to SII and in terms of the thermodynamics of mixtures. This last issue was clearly evidenced by using the Ideal Adsorption Solution Theory, which gives results that compare favorably with those obtained from Raman Scattering and Grand Canonical Monte Carlo simulations. 


\section{Introduction}

Gas clathrate hydrates - commonly known as gas hydrates - are crystalline compounds formed by $\mathrm{H}$-bonded water molecules organized on a network of small and large cages, inside of which gaseous molecules are encapsulated. ${ }^{1}$ Nowadays, these materials have been a research subject of various scientific communities: physical chemistry, astrophysics, geosciences and environmental sciences. ${ }^{2,3}$ Clathrate hydrates are particularly relevant in many chemical engineering applications, such as flow assurance and gas separation technology. ${ }^{1,4}$ The methane hydrate naturally occurs on Earth, mainly on the ocean floor and in the frozen lands near the poles. ${ }^{1,3}$ Natural gas hydrates are also supposed to be present in astrophysical environments like comets, planets and/or in their satellites. ${ }^{5,6}$ For instance, the lack of noble gases in the atmosphere of $\operatorname{Titan}^{7-10}$, the composition of the interior lakes of Enceladus ${ }^{11}$ or the $\mathrm{N}_{2}$ depletion measured in the comet $67 \mathrm{P} / \mathrm{Churyumov-Gerasimenko}{ }^{12}$ may be interpreted with the help of gas hydrate formation. In view of these applications, one of the major properties of interest concerning gas hydrates is their ability to selectively encapsulate molecular species. Such selective trapping has been studied for mixed gas hydrates such as: $\mathrm{CO}_{2}-\mathrm{CH}_{4}{ }^{13,14}, \mathrm{CO}_{2}-\mathrm{N}_{2}{ }^{15,16}, \mathrm{CO}-\mathrm{CO}_{2}{ }^{15}$, or $\mathrm{CO}-\mathrm{N}_{2}{ }^{12,17,18}$. Of particular interest are the carbon monoxide and di-nitrogen species since they are abundant in astrophysical contexts. ${ }^{19-21}$ Moreover, in the industrial context, these molecules are important for gas separation applications. ${ }^{3}$ Even though $\mathrm{CO}$ and $\mathrm{N}_{2}$ share very similar chemical properties (steric hindrance, isoelectronic, mass number), the mixed $\mathrm{CO}-\mathrm{N}_{2}$ gas hydrates are clearly $\mathrm{CO}-$ selective. This selective encapsulation has been reported by Raman scattering experiments ${ }^{17}$ and by molecular simulations ${ }^{12,18}$ in different temperature-pressure domains. Worthwhile to mention is, that pure clathrates of $\mathrm{CO}$ and $\mathrm{N}_{2}$ are first formed in the sI-structure and they transform, in time, to the thermodynamically stable phase sII. ${ }^{22-25}$ In the case of the mixed CO- $\mathrm{N}_{2}$ hydrates ${ }^{26}$, this structural change promotes the $\mathrm{CO}$ molecular selectivity ${ }^{17}$. In this 
paper, this property is documented for the first time by combining Grand Canonical Monte Carlo (GCMC) simulations and Raman Scattering experiments. Especially, the influence of the chemical composition of the gas mixture on the molecular selectivity is investigated. Additionally, an original thermodynamic interpretation based on the Ideal Adsorption Solution Theory (IAST) is provided to help explaining the tendency of CO to be favorably encapsulated.

\section{Methods}

Sample preparation. The $\mathrm{CO}-\mathrm{N}_{2}$ clathrate hydrate was formed by using ultra-pure water (Milli-Q quality) and CO- $\mathrm{N}_{2}$ gas mixture (gas purity of $\mathrm{CO}$ and $\mathrm{N}_{2}$ gas $>99.997 \%$ ) done with a homemade set up composed of two syringe pumps including the PM High Pressure pump (described in the Raman spectroscopy section) with which the two gases are mixed. Gas mixtures are consisting of $10 \%, 25 \%, 50 \% 67 \%$ and $75 \%$ of $\mathrm{CO}$ which correspond to a $[\mathrm{CO}] /\left[\mathrm{N}_{2}\right]$ gas concentration ratio of $0.11,0.33,1,2.03$ and 3 respectively. First, the water was injected inside the sample cell and then cooled until ice formation. The temperature cell was maintained at $270 \mathrm{~K}( \pm 0.1 \mathrm{~K})$ using a modified temperature controlled stage (Linkam Scientific Instruments Ltd., UK). Next, 200 bar of CO-N $\mathrm{N}_{2}$ pressure was applied on ice during 2.5 days. Then the temperature is cooled until $150 \mathrm{~K}$ (Figure S1 line $(1) \rightarrow(2)$ ) and the pressure is decreased until 60 bar (Figure S.1 line $(2) \rightarrow(3)$ ) to ensure that the sample is not decomposed. The first day, the isotherm study from 60 bar to 200 bar is done (at $150 \mathrm{~K}$, Figure S1 line $(3) \rightarrow(2)$ ) and the day after the isobaric data are collected from $150 \mathrm{~K}$ to $270 \mathrm{~K}$ (at 200 bar, Figure S1 line (2) $\rightarrow(1)$ ). These thermodynamic conditions have been chosen by using the phase diagram given in Figure S1. It is important to note that experiments have been done at constant volume and pressure since the sample cell is connected to an automatic 
syringe pump having a reservoir of $100 \mathrm{~cm}^{3}$ (the volume of the cell is around $1 \mathrm{~cm}^{3}$ ). Thus, during all the experiments, the gas mixture is at equilibrium.

Raman spectroscopy. Raman spectra were recorded with a Labram microspectrometer (Horiba Jobin Yvon, Villeneuve d'Ascq, France) using a $514 \mathrm{~nm}$ wavelength laser as excitation source. A 50X objective permitted us to focus the incident laser beam and to collect the Raman scattering. The Raman scattering was dispersed by a holographic grating of 2400 lines/mm (high resolution) and analyzed by a Peltier-cooled CCD detector (Andor, Belfast,UK). Thus, the Raman bands can be measured with a spectral resolution of $0.8 \mathrm{~cm}^{-1}$ (high resolution). The calibration of the spectrometer was done using the $520.7 \mathrm{~cm}^{-1}$ mode of a silicon sample and the $2348.4 \mathrm{~cm}^{-1}$ mode of a neon light. The sample temperatures were maintained at the desired value $( \pm 0.1 \mathrm{~K})$ during the acquisition by using a modified temperature controlled stage (Linkam Scientific Instruments Ltd., UK), including a homemade high-pressure optical cell equipped with a $2 \mathrm{~mm}$ thick sapphire optical window. The sample pressures were controlled by a PM High Pressure pump (Top Industrie, Vaux-le-Penil, France) which can contain $100 \mathrm{~cm}^{3}$ of gas up to 500 bars.

Calculations strategy and details. Monte Carlo simulations were carried out in the Grand Canonical ensemble $(\mu, V, T)$, using the software $\operatorname{GIBBS}^{27}$ and following the strategy already presented elsewhere. ${ }^{18}$ Imposing the chemical potentials, or fugacities as is the case here, of $\mathrm{CO}$ and $\mathrm{N}_{2}$ allows their population in the system to fluctuate through insertion and deletion Monte Carlo moves. In addition, the number of water molecules was kept constant. All species were subjected to translational and rotational Monte Carlo moves. This implies that the hydrate structures were considered as flexible. Moreover, the identity swap move between $\mathrm{CO}$ and $\mathrm{N}_{2}$ molecules was also used to accelerate the convergence of the simulations. This Monte Carlo move is based on the substitution of a molecule of a certain type by a molecule 
of another type, at the same position. The frequencies of the different Monte Carlo moves have been set to $10 \%$ for translation, $10 \%$ for rotation, $40 \%$ for insertion/deletion, and $40 \%$ for identity swap. The initial configurations of structures I and II (sI and sII, respectively) were obtained from the work of Takeuchi et al., ${ }^{28}$ and were made of $2 \times 2 \times 2$ elementary cells. Thus, the sI system included 368 water molecules, forming 64 cages, and the sII system was composed of 192 cages for 1088 water molecules. In other words, the cubic simulation boxes were 24.06 and $34.62 \AA$ long in every direction, for sI and sII respectively, and periodic boundary conditions were applied. The simulations were performed during $10^{7}$ Monte Carlo steps, with an equilibration stage of $10^{6}$ steps. These last number of steps was proven to be sufficiently large to ensure only very small fluctuations of the number of encapsulated molecules, due to the quite small size of the simulated systems and to the use of the identity swap moves. The potential energy was calculated as the sum of the classical pairwise Coulomb and Lennard-Jones contributions of the interaction sites located on the $\mathrm{H}_{2} \mathrm{O}, \mathrm{CO}$ and $\mathrm{N}_{2}$ molecules. The Ewald summation technique was used to compute the Coulomb interactions. The repulsive-dispersive part of the interaction energy was calculated using the following molecular models: the TIP4P-Ewald model for $\mathrm{H}_{2} \mathrm{O}^{29}$, the potential from the work of Piper et al. for $\mathrm{CO}^{30}$, and the TraPPE force field for $\mathrm{N}_{2}{ }^{31}$ (their parameters are given in Table S1). The cutoff for intermolecular interactions was set to half the length of the simulation box and long-range corrections were considered. And, the Lorentz-Berthelot mixing rules were used to derive the interaction between different Lennard-Jones sites.

\section{Results and Discussion}

In the present investigation, the selective property of the mixed gas hydrates is defined with the help of the molecular selectivity, $\beta$. This quantity is defined as the molar concentration 
ratio (or equivalently the molar fraction ratio) of the $\mathrm{CO}$ and $\mathrm{N}_{2}$ in the gaseous and hydrate phase:

$$
\beta=\frac{[\mathrm{CO}]_{\text {hyd }}}{[\mathrm{CO}]_{\text {gas }}} \frac{\left[N_{2}\right]_{\text {gas }}}{\left[N_{2}\right]_{\text {hyd }}}=\frac{x_{C O}}{x_{N_{2}}} / \frac{y_{C O}}{y_{N_{2}}}
$$

where $[\mathrm{A}]_{z}$ is the concentration of $\mathrm{CO}$ or $\mathrm{N}_{2}$ in the $z$-phase, $x_{A}$ and $y_{A}$ are the molar fraction of A in the gaseous and hydrate phase, respectively.
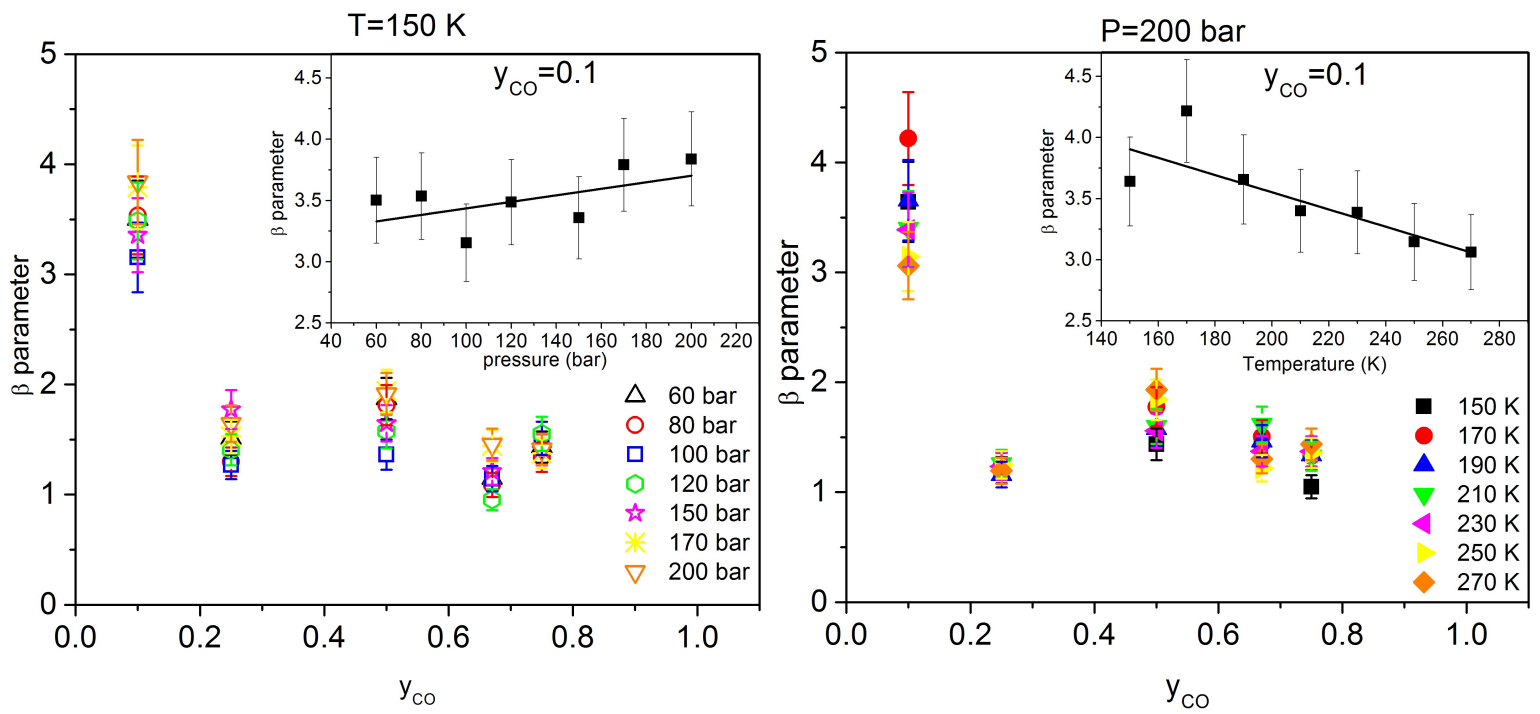

Figure 1. Variation of the molecular selectivity parameter $\beta$ with the molar fraction of carbon monoxide $\mathrm{y}_{\mathrm{CO}}$ in the $\mathrm{CO}-\mathrm{N}_{2}$ gas mixture for the mixed $\mathrm{CO}-\mathrm{N}_{2}$ hydrate along the isotherm at $150 \mathrm{~K}$ (left) and along the isobar at 200 bar (right). The insets show the selectivity parameter $\beta$ for $\mathrm{y}_{\mathrm{CO}}=0.1$ as a function of the pressure (left) and of the temperature (right) and show that for a fixed temperature $\beta$ increases with pressure, while for a fixed pressure $\beta$ decreases with temperature.

Experimentally, the molecular selectivity has been investigated by in-situ Raman scattering of mixed CO- $\mathrm{N}_{2}$ hydrates (see Supporting Information for experimental details). The $\mathrm{CO}$ and $\mathrm{N}_{2}$ Raman bands areas are proportional to the concentration of each molecular specie and to the 
Raman scattering cross sections (i.e. the polarizability variation due to the stretching mode): ${ }^{15,23,24}$

$$
R=\frac{I_{C O}}{I_{N_{2}}}=\frac{[C O]}{\left[N_{2}\right]}\left(\frac{\alpha_{C O}}{\alpha_{N_{2}}}\right)^{2}
$$

where $I_{A}$ is the Raman intensity and $\alpha_{A}$ is the Raman scattering cross section of specie A. Mixed hydrates with various $\mathrm{CO}-\mathrm{N}_{2}$ compositions are formed after two and a half days of pressurization at 200 bar and $270 \mathrm{~K}$ (these values are in the hydrate stability P-T region as shown in Figure S1). The Raman signature of the trapped molecules $\left(v_{C O}^{\text {hyd }}=2135.5 \mathrm{~cm}^{-1}\right.$, $\left.v_{N_{2}}^{\text {hyd }}=2323.9 \mathrm{~cm}^{-1}\right)$ is observed at lower frequency than that of the gas phase $\left(v_{C O}^{\text {gas }}=2141\right.$ $\mathrm{cm}^{-1}, v_{N_{2}}^{\text {gas }}=2328.2 \mathrm{~cm}^{-1}$ ), as shown in Figure $\mathrm{S} 2$. As reported in previous investigations for the $\mathrm{CO}^{23}, \mathrm{~N}_{2}{ }^{24}$ and $\mathrm{CO} / \mathrm{N}_{2}{ }^{17}$ hydrates, this frequency shift is associated to the confinement within the water cages. The frequency lowering upon confinement is related with the small sizes of the $\mathrm{CO}$ and $\mathrm{N}_{2}$ molecules with respect to the cage diameter. ${ }^{17,23,24}$

The molecular selectivity, $\beta$, is obtained by calculating the ratios of the Raman areas, equation (2), for the hydrate $\left(R_{\text {hyd }}\right)$ and the gas phase $\left(R_{\text {gas }}\right)$ :

$$
\beta=\frac{R_{\text {hyd }}}{R_{\text {gas }}}
$$

In this equation, it is assumed that Raman cross sections ratio of equation (2) are similar in the hydrate and gas phases, as reported for $\mathrm{CO}_{2}$ - based mixed hydrates. ${ }^{15}$ Such an assumption could be done thanks to the small size of $\mathrm{CO}$ and $\mathrm{N} 2$ molecules compared to the cage diameter. Henceforth, the $\beta$ value allows determining the species preferentially trapped within the hydrate cages. Specifically, three cases are possible: 
- $\beta>1$, the hydrate is $\mathrm{CO}$ selective (i.e. the $\mathrm{CO}$ to $\mathrm{N}_{2}$ concentration ratios within the hydrate phase is greater than the one within the gas phase),

- $\beta=1$, hydrate selectivity is not observed,

- $\quad \beta<1$, the hydrate is $\mathrm{N}_{2}$ selective.

Figure 1 shows the variation of $\beta$ measured at equilibrium gas compositions along the isotherm $150 \mathrm{~K}$ and along the isobar at 200 bar. Notice that $\beta$ is always greater than 1 irrespective of the pressure, the temperature and gas composition. A slight dependence of the selectivity is observed with the pressure (increase) and with the temperature (decrease), as reported in the insets of Figure 1 in the most selective case $y_{C O}=0.1$. More surprisingly, the CO-selectivity abruptly increases for low $\mathrm{CO}$ gas molar fraction. Previous measurements performed at 200 bar and $270 \mathrm{~K}^{17}$ suggest that this can be associated to a structural change (from sII to sI when $y_{C O}$ increases) for a gas composition of $y_{C O} \sim 0.2$.

For elucidating the unusual increase of $\beta$ at low $\mathrm{CO}$ gas molar fraction, we studied at the molecular level, the thermodynamic properties for mixed $\mathrm{CO}-\mathrm{N}_{2}$ clathrates. For this, we used the Grand Canonical Monte Carlo technique, allowing obtaining the hydrate composition (CO and $\mathrm{N}_{2}$ molecules) by imposing the fugacity of each species. Once equilibrium is reached, the values of $\beta$ are calculated from the molar fraction expression given in equation (1). The reported values of $\beta$ are within a statistical uncertainty below 3\%. Moreover, these values did not present a size dependence of the simulation box.

In agreement with experiments, previous works ${ }^{12,18}$ have shown that $\mathrm{CO}$ molecules are preferentially encapsulated. These studies were focused on low temperatures (50-150) K and fugacities below 10 bar. Under these conditions and for gaseous molar fractions of $0.25,0.5$ and 0.75 , those simulations did not exhibit any significant trend associated to the gas composition. In the present work, GCMC calculations are developed for a series of gas 
compositions characterized by $\xi_{C O}=f_{C O} /\left(f_{C O}+f_{N 2}\right)$ ranging from 0.01 to 0.95 . These calculations were performed at $T=150 \mathrm{~K}$ and with a constant sum of fugacities, $f_{C O}+f_{N_{2}}$, equal to 60 bar. These values $(150 \mathrm{~K}$ and 60 bar) have been chosen according to the thermodynamic conditions used in the experiments. One should note that, for these conditions, the mixed $\mathrm{CO}-\mathrm{N}_{2}$ fluid is not ideal and this non-ideality depends on the composition of the fluid. This implies that the imposed fugacity of each species cannot be directly translated into partial pressure. However, for the composition corresponding to a nonideal fluid $\left(\mathrm{y}_{\mathrm{CO}}=0.75\right)$, we performed a series of NPT Monte Carlo simulations for various pressures between 60 and 200 bar, and we compared the corresponding calculated density of the gas phase with the density obtained in the present GCMC calculations performed at $\mathrm{f}_{\mathrm{CO}}+\mathrm{f}_{\mathrm{N} 2}=60$ bar. Very similar densities where calculated when the total pressure has been fixed at 190 bar in the NPT simulations. This indicates that the real total pressure in the simulations is below 190 bar irrespective of the gas phase compositions considered in our GCMC simulations. The simulation conditions thus always fall in the range of pressures explored by the experiments [60 - 200] bar.

It is worth noting that, in this range, the dependence of the molecular selectivity on the pressure is very small compared to its dependence on the fluid composition, as shown by the inset on the left panel of Figure 1.

For providing a thermodynamic interpretation of the observed (experimental and numerical) gas composition dependence on the molecular selectivity, we used the Ideal Adsorption Solution Theory (IAST). ${ }^{32}$ This is justified by the analogy between enclathration and adsorption formulated by van der Waals and Platteeuw. ${ }^{33}$ Indeed, IAST is a thermodynamic method for predicting mixture compositions of adsorbed phases from exclusively pure (single component) isotherms. Therefore, we also used GCMC simulations to compute the, single- 
guest isotherms for the pure $\mathrm{CO}$ and $\mathrm{N}_{2}$ hydrates at $150 \mathrm{~K}$. The results of these simulations were then used as inputs for the IAST predictions of the corresponding mixed $\mathrm{CO}-\mathrm{N}_{2}$ hydrate composition.
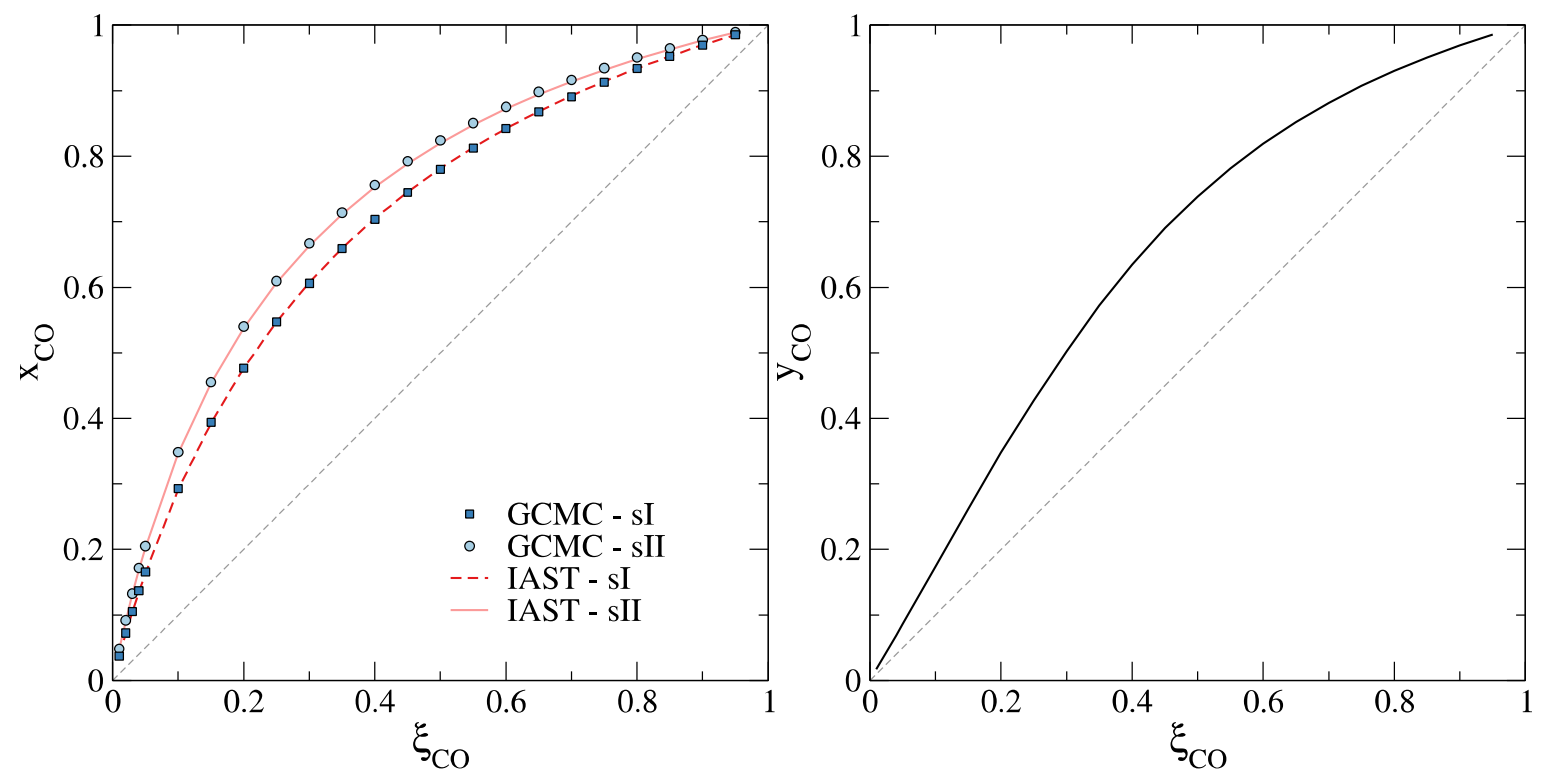

Figure 2. Molar fractions of carbon monoxide in the clathrate phase, for both structures I and II (left) and in the gas phase (right) as functions of $\xi_{C O}=f_{C O} /\left(f_{C O}+f_{N_{2}}\right)$ (this ratio corresponds to the ideal molar fraction in the gas phase), at $150 \mathrm{~K}$ and 60 bar for the sum of imposed fugacities, $f_{C O}+f_{N_{2}}$. The results of the left panel were obtained using GCMC simulations (symbols) and IAST (lines). The right panel displays results from GCMC simulations.

Molar fraction of CO in the hydrate phase for the sI and sII structures, is depicted on the left panel of Figure 2 with respect to $\xi_{C O}$. If the gaseous phase behaves as an ideal solution, the ratio, $\xi_{C O}$, is equal to the molar fraction of $\mathrm{CO}$ in this phase. First, we observe that the predicted mixed hydrate compositions obtained from IAST are in excellent agreement with GCMC simulations for both structures. Thermodynamically, this implies that the CO- $\mathrm{N}_{2}$ mixtures trapped inside hydrates can be considered as ideal mixtures. The comparison for sI is spot-highlighted, whereas a slight deviation can be noted for sII. Moreover, for any given partial fugacity, the $\mathrm{CO}$ molar fraction of sII is higher than for sI. This suggests that the 
molecular selectivity behaves similarly. Notice that $\beta$ is calculated from the gaseous molar fraction (Eq. 1) and not from fugacity ratio (excepting ideal gases). Given the thermodynamic conditions, which are beyond the critical points of $\mathrm{CO}$ and $\mathrm{N}_{2}$, the gas phase cannot be assumed to be ideal. The real composition is then determined for each imposed partial fugacity. This was done, by simulating (with GCMC) the fluid mixture $\mathrm{CO}-\mathrm{N}_{2}$ at conditions imposed to the hydrate. Once the mixture was equilibrated, the molar fraction of $\mathrm{CO}\left(y_{C O}\right)$ was calculated and compared to $\xi_{C O}$. On Figure 2 (right), we can observe that the measured molar fraction for $\mathrm{CO}$ is greater than its ideal counterpart, for all partial fugacities, indicating that the fluid phase is not ideal.

In Figure 3 are given the molecular selectivities by using the real composition of the gas phase. The figure shows, that the mixture is $\mathrm{CO}$ selective in agreement with experimental results. Moreover, the results show that $\beta$ decreases as the gas composition is enriched in CO. Notice that, $\beta$ is always higher for sII than for sI. The predictions from IAST and GCMC simulations for $\beta$ exhibit a remarkable agreement (Figure 3). The comparison between experimental and computed molecular selectivities shows that they spread across similar ranges of values: $1.0 \leq \beta \leq 3.5$. The relevant difference lies in the way CO selectivity change with composition; Experimentally is observed a drastic decrease (jump) from 3.5 to 1.5 at low $y_{C O}$ (while simulated data show a monotonic decrease for structures sI and sII). By considering the simulation curves in Figure 3 the experimental point at $\beta=3.5$ is located above the sII GCMC curve and the point at $\beta=1.5$ below the sI GCMC curve. This suggests that the experimental jump can be originated by a structural change from sI to sII when the CO content in the gas phase is diminished. This ansatz is supported by the experimental results obtained at 200 bar and $270 \mathrm{~K}^{17}$ 


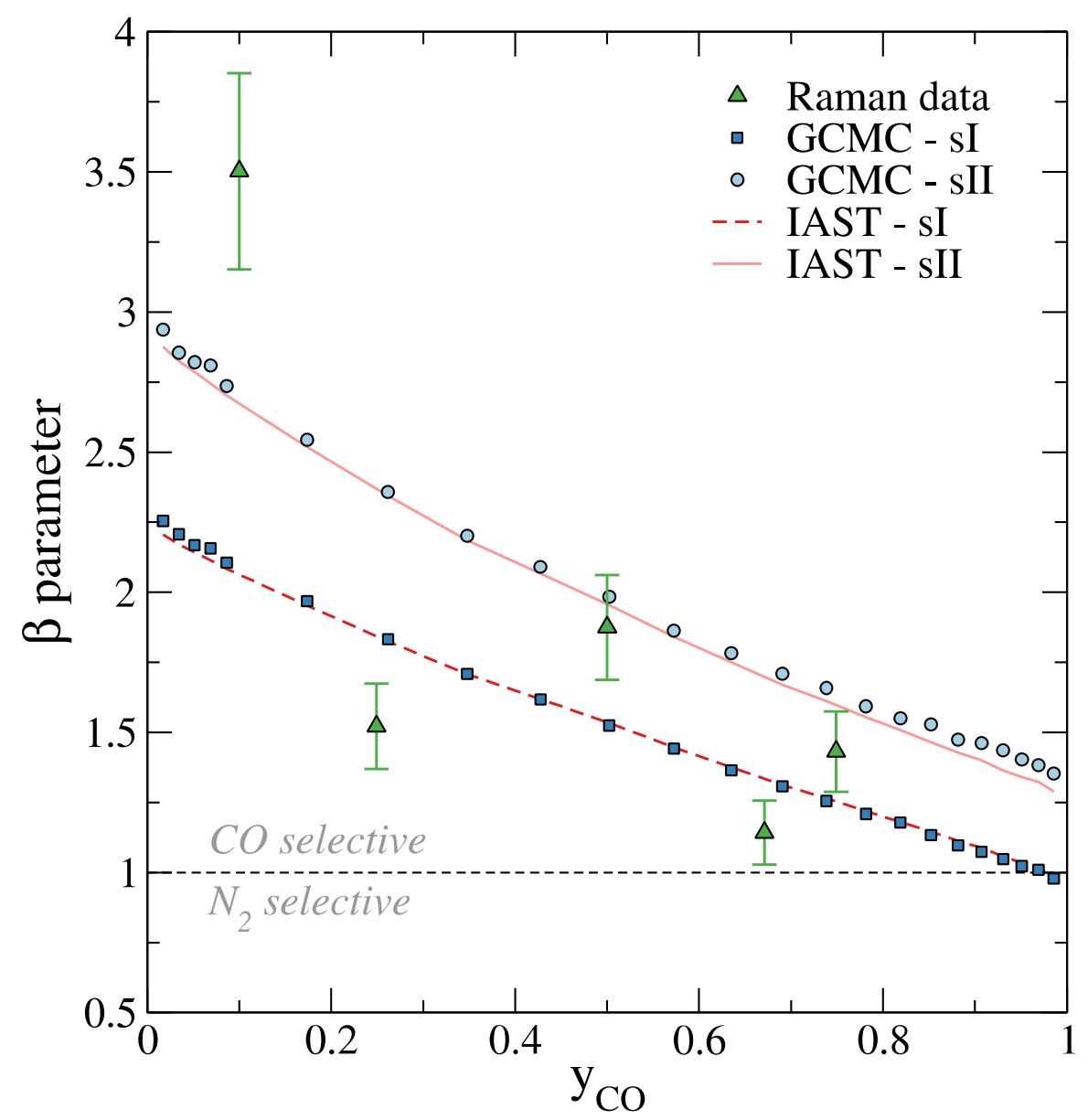

Figure 3. Variation of the molecular selectivity $(\beta)$ with the molar fraction of carbon monoxide in the gas phase, at $150 \mathrm{~K}$ and for $f_{C O}+f_{N_{2}}=60 \mathrm{bar}$, for both structures I and II, using GCMC simulations (circles) and IAST (solid lines). For comparison, the values of $\beta$ obtained from the Raman data at $150 \mathrm{~K}$ and for a pressure of $60 \mathrm{bar}$, are displayed.

\section{Concluding Remarks}

The molecular selectivity of the mixed $\mathrm{CO}-\mathrm{N}_{2}$ hydrate has been investigated by combining Raman scattering and modeling (Grand Canonical Monte Carlo simulation and IAST). Both experimental and simulation approaches yield to determine that the carbon monoxide composition of the hydrate phase was higher than that of the gaseous counterpart by a factor up to 3.5 , irrespective of the $\mathrm{CO}-\mathrm{N}_{2}$ gas mixture composition. Intriguingly, the CO-selectivity smoothly increases when the $\mathrm{N}_{2}$ content increases in the CO- $\mathrm{N}_{2}$ gas mixture. An explanation 
to this increase is given by the ideal mixing rules of the IAST theory. Worth noting, is the abrupt jump in the selectivity at low CO concentration (typically, below 20\%). This result supported by experimental and theoretical results - is associated to a structural change of the mixed hydrate from sI to sII. A novel feature of this study is the use of the IAST for predicting the molecular selectivity in the mixed $\mathrm{CO}-\mathrm{N}_{2}$ hydrate. This approach successfully compares with both Raman spectroscopy and GCMC results. Thanks to the combined approaches, these results provide, not exclusively, new information regarding the selectivity properties of mixed $\mathrm{CO}-\mathrm{N}_{2}$ hydrates, but also a coherent thermodynamic description. A predictive modeling strategy is thus available for studying gas hydrates in natural environments (atmosphere of planets and comets) and for molecular sieving.

\section{ASSOCIATED CONTENT}

\section{Supporting Information.}

The following files are available free of charge.

Experimental details for sample preparation, Raman scattering and additional Raman spectra. Calculation details and strategy. (PDF)

\section{AUTHOR INFORMATION}

The authors declare no competing financial interests.

\section{ACKNOWLEDGMENT}

This paper falls in the frame of MI2C project ANR-15CE29-0016 funded by the French ANR "Agence Nationale de la Recherche". The authors thank IFPEN for providing freely the Monte-Carlo code GIBBS. 


\section{REFERENCES:}

[1] Sloan, E. D.; Koh, C. A. Clathrate Hydrates of Natural Gases; CRC Press: Boca Raton, FL 2008.

[2] Gas Hydrates 1: Fundamentals, Characterization and Modeling; Broseta, D.; Ruffine, L.; Desmedt, A.; Eds.; Wiley-ISTE: London, 2017.

[3] Gas Hydrates 2: Geoscience Issues and Potential Industrial Applications; Ruffine, L.; Broseta, D.; Desmedt, A.; Eds.; Wiley-ISTE: London, 2018.

[4] Koh, C. A.; Sloan, E. D. Natural Gas Hydrates: Recent Advances and Challenges in Energy and Environmental Applications. AIChE J. 2007, 53, 1636-1643.

[5] Mousis, O.; Lunine, J.; Picaud, S.; Cordier, D. Volatile Inventories in Clathrate Hydrates Formed in the Primordial Nebula. Faraday Discuss. 2010, 147, 509-525.

[6] Mousis, O.; Chassefière, E.; Holm, N.; Bouquet, A.; Waite, J.; Geppert, W.; Picaud, S.; Aikawa, Y.; Ali-Dib, M.; Rousselot, P., et al. Methane Clathrates in the Solar System. Astrobiology 2015, 15, 308-326.

[7] Mousis, O.; Lunine, J.; Picaud, S.; Cordier, D.; Waite, J.; Mandt, K. Removal of Titan's Atmospheric Noble Gases by their Sequestration in Surface Clathrates. Astrophys. J., Lett. 2011, 740, L9.

[8] Choukroun, M.; Sotin, C. Is Titan's Shape Caused by its Meteorology and Carbon Cycle? Geophys. Res. Lett. 2012, 39, L04201.

[9] Tobie, G.; Lunine, J. I.; Sotin, C. Episodic Outgassing as the Origin of Atmospheric methane on Titan. Nature 2006, 440, 61-64.

[10] Thomas, C.; Mousis, O.; Ballenegger, V.; Picaud, S. Clathrate Hydrates as a Sink of Noble Gases in Titan's Atmosphere. Astron. Astrophys. 2007, 474, L17-L20.

[11] Bouquet, A.; Mousis, O.; Waite, J.; Picaud, S. Possible Evidence for a Methane Source in Enceladus' Ocean. Geophys. Res. Lett. 2015, 42, 1334-1339. 
[12] Lectez, S.; Simon, J.-M.; Mousis, O.; Picaud, S.; Altwegg, K.; Rubin, M.; Salazar, J. M. A $~ 32-70 \mathrm{~K}$ Formation Temperature Range for the Ice Grains Agglomerated by Comet 67P/Churyumov- Gerasimenko. Astrophys. J., Lett. 2015, 805, L1.

[13] Azimi, A.; Mirzaei, M. Experimental Evaluation and Thermodynamic Modeling of Hydrate Selectivity in Separation of $\mathrm{CO}_{2}$ and $\mathrm{CH}_{4}$. Chem. Eng. Res. Des. 2016, 111, 262-268. [14] Partoon, B.; Sabil, K. M.; Lau, K. K.; Nasrifar; K.; Shariff, A. M. Selective Separation of Methane from Carbon Dioxide through sII Hydrates Formation in a Semibatch Process. Ind. Eng. Chem. Res. 2019, 58(36), 16834-16842.

[15] Petuya, C.; Damay, F.; Desplanche, S.; Talaga, D.; Desmedt, A. Selective Trapping of $\mathrm{CO}_{2}$ Gas and Cage Occupancy in $\mathrm{CO}_{2}-\mathrm{N}_{2}$ and $\mathrm{CO}_{2}-\mathrm{CO}$ Mixed Gas Hydrates. Chem. Comm. 2018, 54, 4290-4293.

[16] Chazallon, B.; Pirim, C. Selectivity and $\mathrm{CO}_{2}$ Capture Efficiency in $\mathrm{CO}_{2}-\mathrm{N}_{2}$ Clathrate Hydrates Investigated by in-situ Raman Spectroscopy. Chem. Eng. J. 2018, 342, 171-183.

[17] Petuya, C.; Desmedt, A. Revealing CO-Preferential Encapsulation in the Mixed CO- $\mathrm{N}_{2}$ Clathrate Hydrate. J. Phys. Chem. C 2019, 123, 4871-4878.

[18] Patt, A.; Simon, J.-M.; Picaud, S.; Salazar, J. M. A Grand Canonical Monte Carlo Study of the $\mathrm{N}_{2}$, CO, and Mixed $\mathrm{N}_{2}-\mathrm{CO}$ Clathrate Hydrates. J. Phys. Chem. C 2018, 122, $18432-$ 18444.

[19] Lodders, K. Solar System Abundances and Condensation Temperatures of the Elements. Astrophys. J. 2003, 591, 1220-1247.

[20] Lunine, J.; Stevenson, D. J. Thermodynamics of Clathrate Hydrates at Low and High Pressures with Application to the Outer Solar System. Astrophys. J., Suppl. Ser. 1985, 58, 493-531. 
[21] Mousis, O.; Lunine, J.; Thomas, C.; Pasek, M.; Marbœuf, U.; Alibert, Y.; Ballenegger, V.; Cordier, D.; Ellinger, Y.; Pauzat, F., et al. Clathration of Volatiles in the Solar Nebula and Implications for the Origin of Titan's Atmosphere. Astrophys. J. 2009, 691, 1780-1786.

[22] Zhu, J.; Du, S.; Yu, X.; Zhang, J.; Xu, H.; Vogel, S. C.; Germann, T. C.; Francisco, J. S.; Izumi, F.; Momma, K., et al. Encapsulation Kinetics and Dynamics of Carbon Monoxide in Clathrate Hydrate. Nat. Commun. 2014, 5, 5128.

[23] Petuya, C.; Damay, F.; Talaga, D.; Desmedt, A. Guest Partitioning in Carbon Monoxide Hydrates by Raman Spectroscopy. J. Phys. Chem. C 2017, 121, 13798-13802.

[24] Petuya, C.; Damay, F.; Chazallon, B.; Bruneel, J.-L.; Desmedt, A. Guest Partitioning and Metastability of the Nitrogen Gas Hydrate. J. Phys. Chem. C 2018, 122, 566-573. [25] Petuya, C.; Damay, F.; Desplanche, S.; Aupetit, C.; Desmedt, A. Ageing and Langmuir Behavior of the Cage Occupancy in the Nitrogen Gas Hydrate. Crystals 2018, $8,145$.

[26] The two clathrate structures existing for the $\mathrm{CO}-\mathrm{N}_{2}$ hydrate differ by the type of cage forming the SI and sII structures. Three types of cages are met: the small $5^{12}$ cages are composed of 12 pentagons of H-bonded water molecules, and the large $5^{12} 6^{2}$ and $5^{12} 6^{4}$ cages are made of 12 pentagons and 2 and 4 hexagons, respectively. The structure sI is a cubic unit cell constituted of two $5^{12}$ and six $5^{12} 6^{2}$ cages and the structure sII of sixteen $5^{12}$ and height $5^{12} 6^{4}$ cages.

[27] Ungerer, P.; Tavitian, B.; Boutin, A. Applications of Molecular Simulation in the Oil and Gas Industry: Monte Carlo Methods, Editions Technip - IFP Publications: Paris, France, 2005.

[28] Takeuchi, F.; Hiratsuka, M.; Ohmura, R.; Alavi, S.; Sum, A. K.; Yasuoka, K. Water Proton Configurations in Structure I, II, and H Clathrate Hydrates Unit Cells. J. Chem. Phys. 2013, 138, 124504. 
[29] Horn, H. W.; Swope, W. C.; Pitera, J. W.; Madura, J. D.; Dick, T. J.; Hura, G. L.; Head-Gordon, T. Development of an Improved Four-Site Water Model for Biomolecular Simulations: TIP4P-Ew. J. Chem. Phys. 2004, 120, 9665-9678.

[30] Piper, J.; Morrison, J.; Peters, C. The Adsorption of Carbon Monoxide on Graphite, Mol. Phys., 1984, 53, 1463-1480. Piper, J.; Morrison, J.; Peters, C. The Adsorption of Carbon Monoxide on Graphite. Mol. Phys. 1984, 53, 1463-1480.

[31] Potoff, J. J.; Siepmann, J. I. Vapor Liquid Equilibria of Mixtures Containing Alkanes, Carbon Dioxide, and Nitrogen. AIChE J. 2001, 47, 1676-1682.

[32] Myers, A. L.; Prausnitz, J. M. Thermodynamics of Mixed-Gas Adsorption. AIChE J. $1965,11,121-127$.

[33] van der Waals, J. H.; Platteeuw, J. C. In Advances in Chemical Physics; Prigogine I. Ed.; Wiley-Interscience: New York, 1959; Vol. 2, pp 1-57.

\section{TOC GRAPHIC}

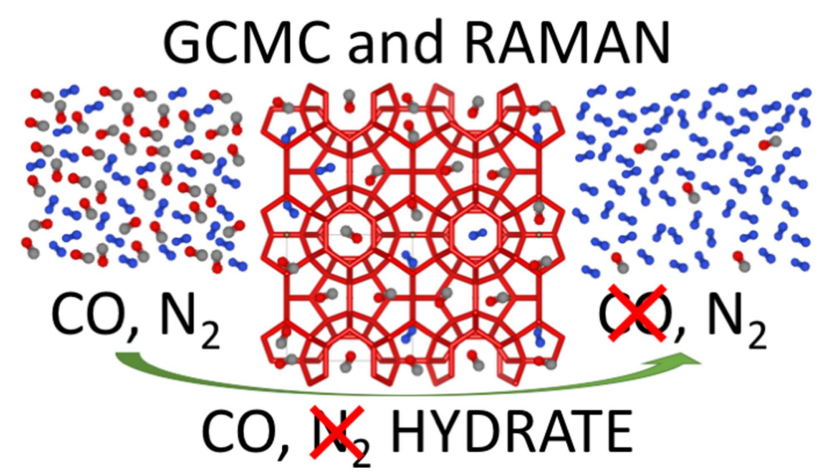

